\title{
Correlation between the Phosphohydrolase Activity of the Escherichia coli Orf135 (NudG) Protein and Mutation Suppression
}

\author{
Hiroyuki Kamiya ${ }^{1}$, Emiko lida and Hideyoshi Harashima \\ Faculty of Pharmaceutical Sciences, Hokkaido University, Sapporo, Japan \\ (Received January 17, 2007; Revised February 15, 2007; Accepted March 15, 2007)
}

The Escherichia coli Orf135 (NudG) protein, a MutT-type enzyme, catalyzes the hydrolysis of 2-hydroxy-dATP and 8-hydroxy-dGTP, and its deficiency causes an increase in the mutation frequency. In this study, Orf135 proteins with substitutions at the Gly-36, Gly-37, Lys-38, Glu-43, Arg-51, Glu-52, Leu-53, Glu-55, and Glu-56 residues, which are conserved in three MutT-type proteins (Orf135, MutT, and MTH1), were each expressed in the orf135strain, and the rpoB mutant frequency upon $\mathrm{H}_{2} \mathrm{O}_{2}$ treatment was examined. The in vivo mutation suppression abilities and the in vitro enzymatic activities obtained in a previous study were compared. The expression of the enzymatically active Orf135 mutants in the orf135- strain tended to reduce the rpoB mutant frequency induced by $\mathrm{H}_{2} \mathrm{O}_{2}$. This result suggests the importance of the phosphohydrolase activity in the suppression of mutations by the Orf135 protein.

Key words: Orf135, phosphohydrolase activity, mutation suppression, nucleotide pool sanitization

\section{Introduction}

Reactive oxygen species (ROS), such as superoxide, hydrogen peroxide, hydroxyl radical, and singlet oxygen, are produced through normal cellular metabolism, and by various environmental mutagens and dietary factors (1-4). Base oxidation occurs in the cellular nucleotide pool as well as in DNA, and the oxidized deoxyribonucleotides induce mutagenic events (5). Specific hydrolysis of oxidized deoxyribonucleotides (nucleotide pool sanitization) is one of the mechanisms to prevent the mutagenesis caused by their misincorporation (6). The Escherichia coli MutT and mammalian MTH1 proteins catalyze the hydrolysis of 8-hydroxy-2' deoxyguanosine $5^{\prime}$-triphosphate $(8-\mathrm{OH}-\mathrm{dGTP})$ to the monophosphate derivative $(7,8)$. Their importance has been shown by increases in the mutation frequency and tumor formation in organisms deficient in these proteins $(9,10)$. Direct evidence that the MutT protein suppresses the mutagenesis caused by $8-\mathrm{OH}-\mathrm{dGTP}$ in vivo was shown by the significantly higher mutation-inducibility of exogenous 8-OH-dGTP in the E. coli mutT strain than in the wild-type (wt) strain (11).

Previously, activities as nucleotide pool sanitization enzymes have been identified for two $E$. coli proteins, Orf135 (NudG) and Orf17 (NudB, NtpA) (12-14). The Orf135 protein catalyzes the hydrolysis of mutagenic deoxyribonucleotides, 2-hydroxy-2' -deoxyadenosine $5^{\prime}$ triphosphate (2-OH-dATP) and 8-OH-dGTP, in vitro $(12,15,16)$. In addition, the lack of the Orf135 protein and its overexpression in $E$. coli cells result in increased and decreased mutation frequencies, respectively (17). The Orf135, MutT, and MTH1 proteins possess a homologous region, the "phosphohydrolase module" or "MutT signature" $(18,19)$. The functional significance of the amino acid residues in this conserved region of the MutT and MTH1 proteins was analyzed (20-22). We previously measured the enzymatic activities of Orf135 mutants with various substitutions in the conserved amino acid sequence (23), and found that some of the mutant proteins had completely lost their activity, while others retained the activity to various degrees.

To know the correlation between the phosphohydrolase activity of the Orf135 protein and mutation suppression, we examined whether the expression of the mutant proteins suppressed the mutator phenotype observed for the orf $135^{-}$strain. The results obtained in this study suggest the importance of this activity in the suppression of mutations in vivo by the Orf135 protein.

\section{Materials and Methods}

Materials: The E. coli strain JD22899, an orf $135^{-}$ strain (lacI ${ }^{\mathrm{q}}$, lacZ $\Delta \mathrm{M} 15-\mathrm{gal}^{-}, F^{-}$, orf135: mini Tn10 (kan)) (Miki et al., unpublished results), was kindly provided by Drs. Yoshihiro Yamamoto and Takeyoshi

${ }^{1}$ Correspondence to: Hiroyuki Kamiya, Faculty of Pharmaceutical Sciences, Hokkaido University, Kita-12, Nishi-6, Kita-ku, Sapporo 060-0812, Japan. Tel: +81-11-706-3733, Fax: +81-11-706-4879, E-mail: hirokam@pharm.hokudai.ac.jp 
Miki. Plasmid DNAs containing a mutant orf135 gene as a fusion gene with GST (glutathione- $S$-transferase), constructed in the previous study (23), were transfected into the JD22899 strain.

Calculation of mutant frequency: A single colony of JD22899, harboring the gene for either the GST or GST-Orf135 fusion protein, was taken from an LB agar plate with kanamycin $(10 \mu \mathrm{g} / \mathrm{mL})$, ampicillin (amp) $(50 \mu \mathrm{g} / \mathrm{mL})$, and isopropyl- $\beta$-D-thiogalactopyranoside (IPTG) $(2 \mu \mathrm{M})$, and was inoculated into $7 \mathrm{~mL}$ of $\mathrm{LB}$ medium containing kanamycin, amp, and IPTG. The E. coli culture was incubated at $37^{\circ} \mathrm{C}$ until the turbidity at $570 \mathrm{~nm}$ reached 0.8 , and then was diluted 10 -fold with prewarmed LB medium containing amp and IPTG. When the turbidity at $570 \mathrm{~nm}$ reached $0.25, \mathrm{H}_{2} \mathrm{O}_{2}$ was added to a final concentration of $2 \mathrm{mM}$, and the culture was incubated at $37^{\circ} \mathrm{C}$ for $30 \mathrm{~min}$. The culture was centrifuged at $2,150 \mathrm{~g}$ for $15 \mathrm{~min}$ at room temperature. The pellet thus obtained was resuspended in the same volume of prewarmed LB medium containing amp and IPTG, and then was diluted 2-fold with prewarmed LB medium containing amp and IPTG. The $E$. coli culture was incubated at $37^{\circ} \mathrm{C}$ until the turbidity at $570 \mathrm{~nm}$ reached 0.85 , and then was placed on ice for $10 \mathrm{~min}$. A portion of the suspension was diluted with ice-cold LB medium and transferred onto an LB agar plate containing amp (a titer plate), which was incubated at $37^{\circ} \mathrm{C}$ for $12 \mathrm{~h}$. Another portion of the suspension was transferred onto an LB agar plate containing rifampicin $(100 \mu \mathrm{g} / \mathrm{mL})$ and amp (a selection plate), which was incubated at $37^{\circ} \mathrm{C}$ for $20 \mathrm{~h}$. The mutant frequency was calculated according to the numbers of colonies on the titer and selection plates.

\section{Results and Discussion}

Mutant Orf135 proteins: Previously, we constructed a series of orf135 genes encoding mutant proteins with substitutions of the amino acid residues that correspond to those essential for MTH1 to exert its 8-OH-dGTPase activity and are conserved in the Orf135, MutT, and MTH1 proteins (23). The Gly-36, Gly-37, Lys-38, Glu-43, Arg-51, Glu-52, Leu-53, Glu-55, and Glu-56 residues of Orf135 were each replaced with Ala, and some amino acids were substituted with their related ones. The wt Orf135 protein catalyzes the hydrolysis of 5-methyl-dCTP (5-MedCTP) and dCTP, in addition to 2-OH-dATP and 8OH-dGTP $(12,13,24)$. The mutant proteins with a substitution at the 36th, 37th, 52nd, and 56th amino acid residues completely lost their activity (23). On the other hand, the mutant proteins with a substitution at the $38 \mathrm{th}, 43 \mathrm{rd}, 51 \mathrm{st}, 53 \mathrm{rd}$, and 55th residues could hydrolyze 5-Me-dCTP. In the current study, we examined the effects of the expression of the mutant Orf135 proteins on mutagenesis in the orf $135^{-}$strain.

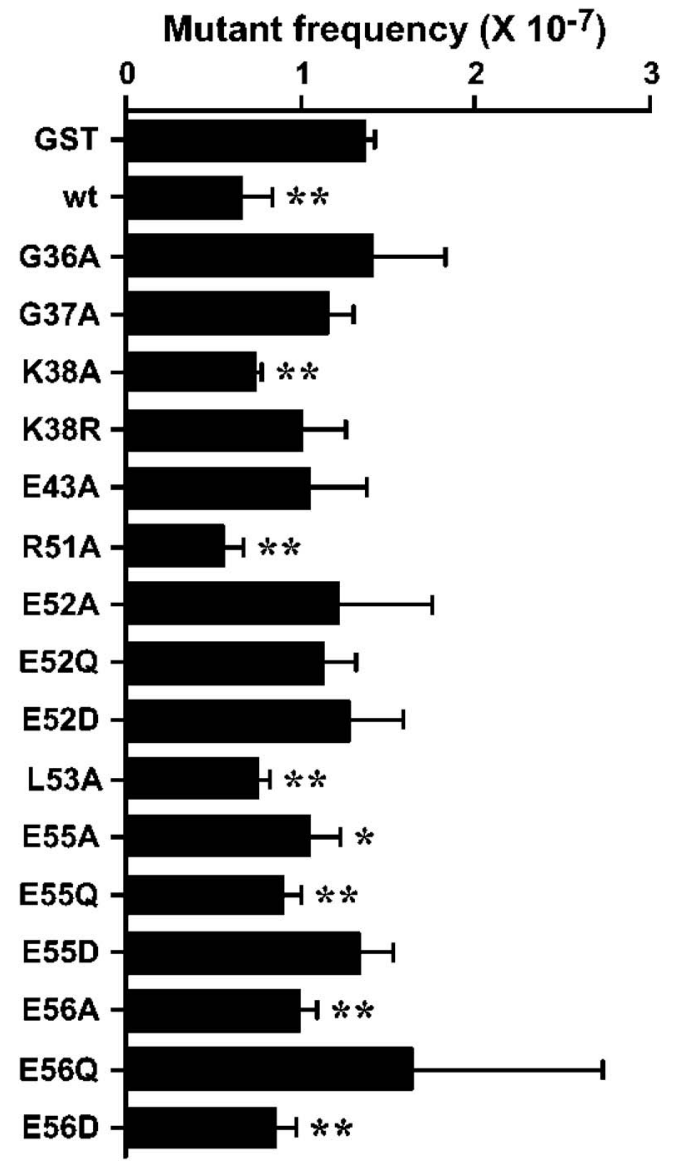

Fig. 1. Suppression of $\mathrm{H}_{2} \mathrm{O}_{2}$-induced mutations by expression of the recombinant Orf135 protein. The orf $135^{-} E$. coli strains, harboring a plasmid for GST or GST-Orf135, were treated with $2 \mathrm{mM} \mathrm{H}_{2} \mathrm{O}_{2}$, as described in the Materials and Methods. Data are expressed as means \pm standard deviation. Asterisks indicate a significant difference versus the GST plasmid, with $\mathrm{p}<0.05\left(^{*}\right)$ or $\mathrm{p}<0.01\left(^{* *}\right)$.

Expression of the recombinant Orf135 protein suppresses mutations: A deficiency in the Orf135 protein causes an increase in the $\operatorname{ROS}\left(\mathrm{H}_{2} \mathrm{O}_{2}\right)$-induced mutation frequency (17). We examined whether the expression of the mutant Orf135 proteins could suppress the mutator phenotype observed for the orf $135^{-}$ strain. Plasmid DNAs containing the gene for either the GST or GST-Orf135 fusion protein were transfected into the orf $135^{-}$strain. The expression of these genes was induced by a treatment with $2 \mu \mathrm{M}$ of an inducer, IPTG. The protein production in the cells was confirmed by sodium dodecylsulfate-polyacrylamide gel electrophoresis (data not shown). The amounts of GST or the GST-Orf135 fusion proteins produced in cells were similar under the culture conditions that were used. These cells were treated with $2 \mathrm{mM} \mathrm{H}_{2} \mathrm{O}_{2}$, and their rpoB mutant frequencies were measured by counting colonies on rifampicin-containing agar plates.

The expression of the wt Orf135 protein in the orf $135^{-}$strain reduced the $\mathrm{H}_{2} \mathrm{O}_{2}$-induced mutant fre- 

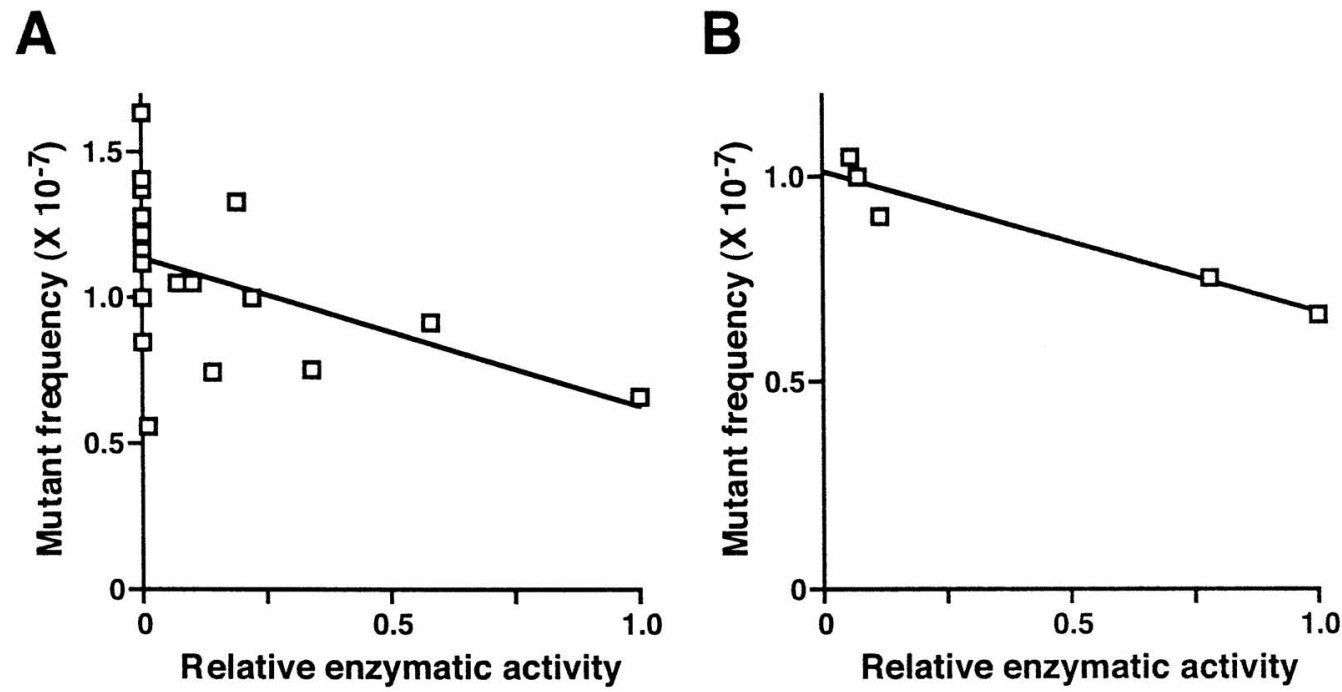

Fig. 2. Correlation between relative phosphohydrolase activity and mutant frequency. The relative enzymatic activity was defined as described in the text. (A) The wt and mutant GST-Orf135 proteins and the GST protein. (B) The wt, K38R, E43A, L53A, and E55Q mutant Orf135 proteins without the GST tag.

quency, as compared with that of the GST protein (Fig. 1 ), as reported previously (17). In addition, some of the mutant Orf135 proteins decreased the $r p o B$ mutant frequency. The degrees of the reduction in the $\mathrm{H}_{2} \mathrm{O}_{2}$ induced mutant frequency varied between the mutants tested (Fig. 1). The expression of the K38A, R51A, L53A, E55A, E55Q mutant proteins in the orf135strain significantly reduced the $\mathrm{H}_{2} \mathrm{O}_{2}$-induced mutant frequency. These mutant proteins were enzymatically active in vitro (23).

Correlation of phosphohydrolase activity and mutation suppression: Next, we examined the relationship between the in vitro phosphohydrolase activities of the mutant Orf135 proteins fused to GST (23) and the $\mathrm{H}_{2} \mathrm{O}_{2}$-induced $r p o B$ mutant frequencies when they were expressed in orf $135^{-}$bacteria (Fig. 1). The 5-MedCTPase and dCTPase activities were measured with the GST-Orf135 proteins, purified on a small scale (Fig. 3 in reference 23). These activities of each mutant protein were normalized to those of the wt protein $(\mathrm{wt}=$ 1.0), and the averages of the normalized 5-Me-dCTPase and dCTPase activities were defined as the relative enzymatic activities. As shown in Fig. 2A, there is a correlation between the relative enzymatic activities and the $\mathrm{H}_{2} \mathrm{O}_{2}$-induced mutant frequencies. The Pearson's correlation coefficient was calculated to be -0.47 , and this value is statistically significant $(\mathrm{p}<0.05)$.

Previously, the K38R, E43A, L53A, and E55Q mutant proteins (without the GST tag) were examined in detail for their 5-Me-dCTPase, dCTPase, 2-OHdATPase, and 8-OH-dGTPase activities (Fig. 4 in reference 23). These activities of each mutant protein were normalized to those of the wt protein $(w t=1.0)$, and the averages of the normalized hydrolysis activities were defined as the relative enzymatic activities. Again, we analyzed the relationship between the relative enzymatic activities of the wt and the four mutant proteins, and the mutant frequencies when they were expressed in orf $135^{-}$bacteria (Fig. 1). As shown in Fig. 2B, a good correlation exists between the enzymatic activities and the $\mathrm{H}_{2} \mathrm{O}_{2}$-induced mutant frequencies. The Pearson's correlation coefficient was calculated to be -0.96 , and it is statistically significant $(p<0.05)$. Significant $(p<0.05)$ correlations were also observed when each of the 5-Me-dCTPase, dCTPase, 2-OH-dATPase, and 8$\mathrm{OH}$-dGTPase activities was used as the phosphohydrolase activity (the correlation coefficients were -0.94 , $-0.96,-0.95$, and -0.89 , respectively; data not shown). Thus, the results of these experiments suggest that the Orf135 protein could suppress the ROS-induced mutagenesis derived from oxidized deoxyribonucleotide(s), through their elimination by its phosphohydrolase activity.

The weaker correlation between the $\mathrm{H}_{2} \mathrm{O}_{2}$-induced mutant frequencies and the phosphohydrolase activities of the mutant GST-Orf135 proteins may be explained by the fact that the in vitro enzyme assay was not optimized. Alternatively, the possible presence of unknown substrate(s) in E. coli cells treated with $\mathrm{H}_{2} \mathrm{O}_{2}$ may explain the weaker correlation between the mutant frequencies and the phosphohydrolase activities of the mutant GST-Orf135 proteins. Since 8-hydroxy-dATP and formamidopyrimidine-dGTP were not hydrolyzed by Orf135 and were nonmutagenic in E. coli $(25$, Kamiya et al., unpublished results), they are not candidates for the unknown substrate(s).

In this study, a significant relationship between the $\mathrm{H}_{2} \mathrm{O}_{2}$-induced mutant frequencies and the phospho- 
hydrolase activities of the mutant Orf135 proteins in vitro was demonstrated. Our results suggest that the Orf135 protein suppressed the ROS-induced mutagenesis derived from oxidized deoxyribonucleotides in E. coli cells, through their elimination by its phosphohydrolase activity.

Acknowledgements: We thank Drs. Yoshihiro Yamamoto and Takeyoshi Miki for the E. coli strain JD22899. This work was supported in part by Grantsin-Aid from the Ministry of Education, Culture, Sports, Science and Technology of Japan.

\section{References}

1 Ames BN. Dietary carcinogens and anticarcinogens. Science. 1983; 221: 1256-64.

2 Ames BN, Gold LS. Endogenous mutagens and the causes of aging and cancer. Mutat Res. 1991; 250: 3-16.

3 Henle ES, Linn S. Formation, prevention, and repair of DNA damage by iron/hydrogen peroxide. J Biol Chem. 1997; 272: 19095-8.

4 Hiraku Y, Murata M, Kawanishi S. Role of oxidative DNA damage in dietary carcinogenesis. Genes Environment. 2006; 28: 127-40.

5 Kamiya H. Mutagenic potentials of damaged nucleic acids produced by reactive oxygen/nitrogen species: Approaches using synthetic oligonucleotides and nucleotides. Nucleic Acids Res. 2003; 31: 517-31.

6 Sekiguchi M, Tsuzuki T. Oxidative nucleotide damage: consequences and prevention. Oncogene. 2002; 21: 8895904.

7 Maki H, Sekiguchi M. MutT protein specifically hydrolyses a potent mutagenic substrate for DNA synthesis. Nature. 1992; 355: 273-5.

8 Mo J-Y, Maki H, Sekiguchi M. Hydrolytic elimination of a mutagenic nucleotide, 8-oxodGTP, by human 18kilodalton protein: sanitization of nucleotide pool. Proc Natl Acad Sci USA. 1992; 89: 11021-5.

9 Yanofsky C, Cox EC, Horn V. The unusual mutagenic specificity of an E. coli mutator gene. Proc Natl Acad Sci USA. 1966; 55: 274-81.

10 Tsuzuki $\mathrm{T}$, Egashira A, Igarashi, H. Iwakuma $\mathrm{T}$, Nakatsuru $Y$, Tominaga $Y$, Kawate $H$, Nakao $K$, Nakamura K, Ide F, Kura S, Nakabeppu Y, Katsuki M., Ishikawa T, Sekiguchi M. Spontaneous tumorigenesis in mice defective in the MTH1 gene encoding 8-oxodGTPase. Proc Natl Acad Sci USA. 2001; 98: 11456-61.

11 Kamiya $H$, Ishiguro $C$, Harashima $H$. Increased $\mathrm{A}: \mathrm{T} \rightarrow \mathrm{C}: \mathrm{G}$ mutations in the mut T strain upon 8-hydroxydGTP treatment: Direct evidence for MutT in the prevention of mutations by oxidized dGTP. J Biochem. 2004; 136: 359-62.

12 Kamiya $\mathrm{H}$, Murata-Kamiya $\mathrm{N}$, Iida E, Harashima $\mathrm{H}$. Hydrolysis of oxidized Nucleotides by the Escherichia coli Orf135 protein. Biochem Biophys Res Commun.
2001; 288: 499-502.

13 Fujikawa $K$, Kasai $H$. The oxidized pyrimidine ribonucleotide, 5-hydroxy-CTP, is hydrolyzed efficiently by the Escherichia coli recombinant Orf135 protein. DNA Repair. 2002; 1: 571-6.

14 Hori M, Fujikawa K, Kasai H, Harashima H, Kamiya H. Dual hydrolysis of diphosphate and triphosphate derivatives of oxidized deoxyadenosine by Orf17 (NtpA), a MutT-type enzyme. DNA Repair. 2005; 4: 33-9.

15 Iida E, Satou K, Mishima M, Kojima C, Harashima H, Kamiya H. Amino acid residues involved in substrate recognition of the Escherichia coli Orf135 protein. Biochemistry. 2005; 44: 5683-9.

16 Inoue $M$, Kamiya $H$, Fujikawa $K$, Ootsuyama $\mathrm{Y}$, Murata-Kamiya N, Osaki T, Yasumoto K, Kasai H. Induction of chromosomal gene mutations in Escherichia coli by direct incorporation of oxidatively damaged nucleotides. J Biol Chem. 1998; 273: 11069-74.

17 Kamiya H, Iida E, Murata-Kamiya N, Yamamoto Y, Miki T, Harashima H. Suppression of spontaneous and hydrogen peroxide-induced mutations by a MutT-type nucleotide pool sanitization enzyme, the Escherichia coli Orf135 protein. Genes Cells. 2003; 8: 941-50.

18 Nakabeppu Y. Molecular genetics and structural biology of human MutT homolog, MTH1. Mutat Res. 2001; 477: 59-70.

19 Bessman MJ, Frick DN, O'Handley SF. The MutT proteins or "Nudix" hydrolases, a family of versatile, widely distributed, "housecleaning", enzymes. J Biol Chem. 1996; 271: 25059-62.

20 Cai JP, Kawate H, Ihara K, Yakushiji H, Nakabeppu Y, Tsuzuki T, Sekiguchi M. Significance of the conserved amino acid sequence for human MTH1 protein with antimutator activity. Nucleic Acids Res. 1997; 25: 1170-6.

21 Fujii Y, Shimokawa H, Sekiguchi M, Nakabeppu Y. Functional significance of the conserved residues for the 23-residue module among MTH1 and MutT family proteins. J Biol Chem. 1999; 274: 38251-9.

22 Shimokawa H, Fujii Y, Furuichi M, Sekiguchi M, Nakabeppu Y. Functional significance of conserved residues in the phosphohydrolase module of Escherichia coli MutT protein. Nucleic Acids Res. 2000; 28: 3240-9.

23 Kamiya H, Iida E, Harashima H. Important amino acids in the phosphohydrolase module of Escherichia coli Orf135. Biochem Biophys Res Commun. 2004; 323: 1063-8.

24 O'Handley SF, Dunn CA, Bessman MJ. Orf135 from Escherichia coli is a nudix hydrolase specific for CTP, dCTP, and 5-methyl-dCTP. J Biol Chem. 2001; 276: 5421-6.

25 Hori $\mathrm{M}$, Ishiguro $\mathrm{C}$, Harashima $\mathrm{H}$, Kamiya $\mathrm{H}$. In vivo mutagenicities of damaged nucleotides produced by nitric oxide and ionizing radiation. Biol Pharm Bull. 2005; 28: $520-2$. 